\title{
OBSTETRICAL ACUTE RENAL FAILURE;
}

\author{
Analysis and outcome of patients in tertiary care hospital
}

Dr. Ambreen Ghori, Dr. Chandra Madhudas, Dr. Ferkhunda Khurshid, Dr. Jamila Siakndari, Dr. Tarachand Devrajani, Dr. Syed Zulfiquar Ali Shah.

ABSTRACT.....Background \& Objective: Acute renal failure is one of serious complication in pregnancy, in first trimester is usually related to unregulated and septic miscarriage while in third trimester it is due to obstetric complications. This prospective case serious descriptive study was conducted to determine the frequency, etiology and outcome of patients suffering from acute renal failure. Settings: Department of Gynecology \& Obstetric at Liaquat University Hospital Hyderabad. Duration: One year (from 1st June 2011 to 31st May 2012) Patients and Methods: Patients admitted in labor room during antepartum, intrapartum or post partum period were scrutinized by history, clinical examination, and investigations. Those with urine output less than 50cc in 24hours were defined as case of ARF. Predesigned proforma filled to analyze etiology and outcome of patients with acute renal failure. Results: Out of 3220 patients admitted, 35 patients presented with acute renal failure giving incidence of $1.080 \%$. APH(28.57\%), PPH(25.7\%), P.sepsis (14.28\%) and Hypertensive disorder(5.14\%) were leading cause of ARF. 60\% patients recovered from injury and mortality in these patients were $11.4 \%$. Conclusions: Poor health care facilities and lack of quality antenatal healthcare clinics were the major identified causes.

Key words: Acute Renal failure, Obstetrical complication, Irreversible Renal failure.

Article Citation

Ghori A, Madhudar C, Khurshid F, Siakndari J, Devrajani T, Shah SZA. Obstetrical Acute Renal Failure; Analysis and outcome of patients in tertiary care hospital. Professional Med J 2013;20(3): 429-432.

\section{INTRODUCTION}

Acute renal failure is one of serious complication in pregnancy ${ }^{1}$. In first trimester; it is usually related to unregulated and septic miscarriage while in third trimester it is usually due to obstetric complications. In developed world the incidence of acute renal failure in pregnancy has declined over past recent decade. It is less than $1 \%$ of all western society ${ }^{2}$. This is because of several factors has contributed to marked improvement in the incidence and survival in pregnancy related acute renal failure including the significant decrease in septic miscarriage and more successful early intervention in management of complicated pregnancy ${ }^{3}$. So far developing countries scenario has not changed much more in last few decades. In a study in North India $22 \%$ of cases of Acute renal failure were of obstetric origin and maternal mortality in these patients were $50 \%{ }^{4}$. In another study from India incidence of cortical necrosis were $24 \%{ }^{5}$, while it is reported $13 \%$ by Ramzan in one study from Pakistan ${ }^{6}$. The most common cause of Acute renal failure in developing countries in obstetric care units are severe sepsis and hemorrhagic shock and mortality in these patients is about $70 \%^{7}$. The incidence of obstetric related ARF in developing countries like Pakistan has not changed significantly. There is no such Data to compare. There are only few articles showing pregnancy related Acute renal failure $7-10 \%^{8}$. Mortality and morbidity in obstetric acute renal failure depends on under lying renal lesion and associated complications .It is high when associated with HELLP syndrome, Severe PET, Sepsis , DIC and $\mathrm{PPH}$. Recovery depend on type of damage. It is good in acute tubular necrosis as compare to bilateral renal cortical necrosis 9 . The aim of this study is to pick - up magnitude of problem and to develop a strategy to prevent it.

\section{PATIENTS AND METHODS}

This prospective case serious descriptive study was conducted in obstetric unit II, LUMHS during June 2011 to May 2012. Departmental approval for study was obtained. The inclusion criteria of the study were the cooperative patients regardless of maternal and gestational age admitted in the labor room during antepartum, intrapartum or post partum period and 
had interest to participate in the study were scrutinized by history, clinical examination, and investigations. The exclusion criteria of the study were the known cases of renal failure / already on hemodialysis or the patients with malignancy and on chemotherapy and the patients with known glomerular or autoimmune disease. After fulfilling the inclusion criteria, those with urine output less than $50 \mathrm{cc}$ in 24 hours were defined as case of ARF. Predesigned Performa filled to analyze etiology and outcome of patients with acute renal failure. The data was entered, saved and analyzed in SPSS Version 16 and the frequency and percentage (\%) was calculated.

\section{RESULTS}

Out of 3220 patients admitted, 35 patients presented with acute renal failure giving incidence of $1.080 \%$. Table-I showed etiological factors for acute renal failure. Obstetric hemorrhage was responsible for ARF in more than $50 \%$ of cases followed by $P$.sepsis 05(14.28\%), Hypertensive Disorder 05(14.28\%) and anaphylactic reaction 04(11.42\%). Table 2 shows outcome of these patients. $57.14 \%$ (20) of patient completely recovered from injury, $17.14 \%$ (6) partially recovered, $14.28 \%$ (5) had permanent damage and the mortality recorded in our patient was $11.4 \%$.

\begin{tabular}{|l|c|c|}
\hline \multicolumn{1}{|c|}{ Cause } & No & Percentage \\
\hline PPH & 09 & $25.71 \%$ \\
\hline APH & 10 & $28.57 \%$ \\
\hline P. Sepsis & 05 & $14.28 \%$ \\
\hline Hypertension & 05 & $14.28 \%$ \\
\hline Anaphylactic Reaction & 04 & $11.42 \%$ \\
\hline HELLP Syndrome & 02 & $5-714 \%$ \\
\hline Total & 35 & $100 \%$ \\
\hline
\end{tabular}

Table-I. Causes of acute renal failure

\begin{tabular}{|l|c|c|}
\hline \multicolumn{1}{|c|}{ Outcome } & No & Percentage \\
\hline Complete Recovery & 20 & $57.14 \%$ \\
\hline Partial Recovery & 06 & $17.14 \%$ \\
\hline $\begin{array}{l}\text { No recovery (irreversible } \\
\text { bilateral Cortical neurosis) }\end{array}$ & 05 & $14.28 \%$ \\
\hline Total no: of Patients died. & 04 & $11.4 \%$ \\
\hline \multicolumn{2}{|c|}{ Table-II. Outcome of patients with ARF } \\
\hline
\end{tabular}

\section{DISCUSSION}

Maternal mortality and morbidity is an embarrassing reminder of global in equality; there is no other public health statics for which the Gulf between the developed and developing world is so large. Apart from APH, PPH, Sepsis and Eclampsia mortality and morbidity associated with acute renal failure shows marked difference between developed and developing countries. In developed world during 1950-1960,22\% cases of all ARF were obstetric in origin and mortality in these patients were between $16-48 \%{ }^{10}$, while Strette quoted $0.5 \%$ obstetric renal failure of total ARF cases and no maternal death between year 1988-1994 ${ }^{11}$. It looks that it is vanishing from industrialized world. There are several factors which have lead to improvement, like improvement in Antenatal care, decrease Post abortion sepsis and timely recognition and management of High risk pregnancies. Although obstetrical ARF is also on decline in developing countries still it is one of the main causes of acute renal failure in this part of world ${ }^{12}$.

Frequency of Acute renal failure in current study was $1.08 \%$ while it was reported $2.8 \%$ from Peshawar ${ }^{13}$, $0.8 \%$ from Karachi ${ }^{14}$ while in a study from parent university $36 \%$ of Acute renal failure admitted in Nephrology unit were because of obstetric reasons ${ }^{15}$. Another study from same university shows that $2 \%$ patients with Abruption placenta develop acute renal failure ${ }^{16}$ while the recent review of published literature by Waiker et a ${ }^{17}$ shows pregnancy related ARF has not been listed as one of cause of ARF in developing 
countries $^{16}$. Main reason of Acute renal failure in current study was obstetric hemorrhage similar to study by Akhtar $^{13}$ from Peshawer and Ali from Frontier Province ${ }^{8}$. Obstetrical hemorrhage is leading cause of morbidity and mortality in developing countries from decades and it is still as proved by the current study. $19.19 \%$ of patients was with hypertensive disorder and HELLP syndrome similar to study from same university by Ansari MR, et al ${ }^{15}$ while it was responsible for $12.5 \%$ and $16.66 \%$ cases of acute renal failure from Karachi ${ }^{14}$ and Peshwar ${ }^{18}$. Lack of quality of Antenatal care and late referral in critical condition were found to be responsible for PIH related ARF. Sepsis is part of past in developed countries but it is still common in developing countries. $1428 \%$ cases of ARF in current study were due to septicemia. It is preventable and treatable illness, however, timely recognition is important so for recovery is concerned there were complete recovery in $60 \%$ cases, partial recovery in $17.14 \%$ and $14.28 \%$ had permanent damage. This is comparable to study by Ansari MR, et al ${ }^{15}$ study differ from study by Bibi S, et al in which $50 \%$ patient had irreversible damage ${ }^{16} .4(11.4 \% 0$ of our patients could not survive comparable with that of Waikar SS, et al ${ }^{17}$ but less than study of Khalil M, et $\mathrm{al}^{18}$.

\section{CONCLUSIONS}

Keeping in front the results of current study, it looks that obstetrical renal failure is a major health problem in our set up, which is now a rare entity in developed countries. However, difficulties associated with overall health system and physical infrastructure, political and high illiteracy rate etc creates hindrance in smooth development and there for difficulties in achieving goals in developing countries. This calls for an improvement in existing health care facilities and public awareness programmes and better care in public sector hospitals.

\section{Copyright(C) 17 Jan, 2013.}

\section{REFERENCE}

1. Agrahakar M, Agrahakar A, Kelly B, Mandayam AS,
Bameja K. Renal disease and pregnancy [on line] 2006 (cited 2007 may 10). Available from http,/www.emedicine.com/md/topic 3253.htm.

2. Krene KN, MD. Arch Intern Med Vol 148, No 1988.

3. Drakeley AJ, LeRoux PA, Anthony J. Acute renal failure complicating severe preeclampsia requiring admission to an obstetric intensive care unit. Am J Obstetric Gynecol 2002; 186:253-6.

4. Chugh KS, Singhal PC, Sherme BK et al: Acute renal failure of obstetric origin. Obstet Gynecol D, Bourneriesf 1974; 1188:331-336.

5. Parkash j, Tripathik, Panday Lk, Gadela SR, Usha. Renal cortical necrosis in pregnancy-related acute renal failure. J Indian Med Assoc. 1996; 94:227-9.

6. Ramzan M, Sameeh JK, Ghiasuddin. One year renal outcome of pregnancy related kidney failure. $\mathrm{J}$ Pakistan Inst. Med Sci 2004: 2004:15:834-8.

7. Diiazode Leon M , Moreno SA, Gonzalez Diaz DJ. Severe sepsis as cause of acute renal failure. Neprologica 2006;26(4) 439-44.

8. Ali A, Zafer S, Mehmood A, Nisar A. Obstetrical acute renal failure from frontier Provience: A 3 years prospective study. J post Grad Med Inst 2004. 18: 10917.

9. Medias NE, Donohoe JF, Harrington JT. Post Ischemic acute renal failure. Ins Brenner BM, Lazarus JM, eds. Acute renal failure. 2nd. New York: Churchill Livingstons. 1988:pp; 251.

10. Pertuiset N, Genevel D, Grunfeld JP, : Acute renal failure in pregnancy. An update semin Nephrol 1984;4: 232-239.

11. Strette P, Bessol, Cenevese C: Is pregnancy related acute renal failure a disappearing clinical entity? Ren Fail 1996; 18:575-84.

12. Parkash J, Kumar H, Sinha Dk, Kedalaya PG, Panday LK, Srivasta PK. et al. Acute renal failure in pregnancy in developing country: Twenty years of experience. Ren Fail 2006; 28(4); 309-13.

13. Ali A, Ali M, Usman Ali M. Obstetrical associated renal 
cortical necrosis : though un common but not rare. JAMC 2010;22(3):74-76.

14. Tariq G, Naz S, Soomro N. Acute renal failure in obstetric care unit. Pakistan journal of surgery 2009; 25(4): 283-285.

15. Ansari RM, Laghari SM, Solangi BK. Acute renal failure in pregnancy: One year observational study at liaquat university hospital, Hyderabad. J Pak Med Assoc 2008; 58(2) : 61-64.
16. Bibi S, Ghaffar S, Pir AM, Yousfani S. Risk factors and clinical out come of placental abruption. A retrospective analysis. J Pak Med Assoc 2009;59 (10);672-74.

17. Waikar SS, Lui KD, Chertow GM. Diagnosis, epidiomology and outcome of acute kidney injury. Clin J Am Soc Nephrol 2008; 3:844-861.

18. Khalil M, Azhar A, Anwar N. Aetiology maternal and fetal out come in $\mathbf{6 0}$ cases of obstetrical acute renal failure. JAMC 2009; 21(4): 46-49.

\section{AUTHOR(S):}

\section{DR. AMBREEN GHORI}

Department of Obstetrics \& Gynaecology

Liaquat University of Medical \& Health Sciences, Jamshoro.

2. DR. CHANDRA MADHUDAS

Department of Obstetrics \& Gynaecology

Liaquat University of Medical \& Health Sciences, Jamshoro.

3. DR. FERKHUNDA KHURSHID

Department of Obstetrics \& Gynaecology

Liaquat University of Medical \& Health Sciences, Jamshoro.

4. Dr. Jamila Siakndari

Department of Obstetrics \& Gynaecology

Liaquat University of Medical \& Health Sciences, Jamshoro.
5. Dr. Tarachand Devrajani

Department of Medicine

Liaquat University of Medical \& Health Sciences, Jamshoro.

6. Dr. Syed Zulfiquar Ali Shah

Department of Medicine

Liaquat University of Medical \& Health Sciences, Jamshoro.

Correspondence Address:

Dr. Syed Zulfiquar Ali Shah

House No. 279, Doctors Colony Hirabad, Hyderabad,

Sindh, Pakistan.

zulfikar229@hotmail.com

Article received on: 13/11/2012

Accepted for Publication: $17 / 01 / 2013$ Received after proof reading: 15/03/2013

\section{PREVIOUS RELATED STUDIES}

Qurban Ali Shaikh, Nisar Ahmed Shaikh, Akbar Ali Soomro, Ghulam Shabir Shaikh, Abdul Rasheed Shaikh. PREGNANCY RELATED ACUTE RENAL FAILURE; AN EXPERIENCE AT NEPHRO-UROLOG DEPARTMENT CHANDKA MEDICAL COLLEGE TEACHING HOSPITAL LARKANA(Original) Prof Med Jour 15(1) 129 - 132 Jan, Feb, Mar, 2008.

Qurban Ali Shaikh, Nisar Ahmed Shaikh, Akbar Ali Soomro, Ghulam Shabir Shaikh, Abdul Rasheed Shaikh. ACUTE RENAL FAILURE: AN EXPERIENCEAT NEPHRO-UROLOGY DEPARTMENT CHANDKA MEDICAL COLLEGE HOSPITAL LARKANA (Original) Prof Med Jour 15(2) 229-233Apr, May, Jun 2008. 